\title{
COPING STRATEGIES AND POST-TRAUMATIC GROWTH IN PARAMEDICS: MODERATING EFFECT OF SPECIFIC SELF-EFFICACY AND POSITIVE/NEGATIVE AFFECTIVITY
}

\author{
Erika JURIŠOVÁ \\ Department of Psychological Sciences, Faculty of Social Sciences and Health Care \\ Constantine the Philosopher University in Nitra \\ Kraskova 1, 94974 Nitra, Slovak Republic \\ E-mail: ejurisova@ukf.sk
}

\begin{abstract}
The aim of the study was to identify relations between coping strategies applied in a situation of confrontation with stressful situation and post-traumatic growth (PTG) in the group of paramedics, and to analyze moderating effects of specific self-efficacy and affectivity. Sample: 62 paramedics, between age 21-53 $(M=35.91, S D=8.97)$. Methods: Posttraumatic Growth Inventory PTGI (Tedeschi \& Calhoun, 1996); Multidimensional coping inventory, COPE (Carver, Scheier, \& Weintraub, 1989); The General Self-Efficacy Scale, GSES (Jerusalem \& Schwarzer, 1981); Positive and Negative Affect Scale, PANAS (Watson, Clark, \& Tellegen, 1988). Results: Rate of the total PTG in the sample indicates the presence of PTG at the average. We found positive relations between coping strategies: active coping, planning, suppression of competing activities, restraint coping, seeking social support - instrumental, use of emotional social support, religious coping, focus on and venting of emotions, behavioral disengagement, substance abuse (smoking) and PTG; we identified moderation effects of self-efficacy and positive affectivity on the relation between coping and PTG.
\end{abstract}

Key words: post-traumatic growth, coping strategies, specific self-efficacy, affectivity, paramedics

\section{Coping Strategies and Post-Traumatic Growth in Paramedics: \\ Moderating Effect of Specific Self-Efficacy and Positive/Negative Affectivity}

The experts have associated experiencing various difficult life events and situations with negative effects that naturally follow, even though people may as a result quite possibly grow in the psychological, emotional and spiritual aspect.

In the literature, the terms for positive consequences that subsequently arise from negative life experiences are labelled as per- ceiving, construing, or finding benefits (Affleck \& Tennen, 1996; Antoni et al., 2001; McMillen et al., 1995; Tennen et al., 1992), thriving (Abraído-Lanza et al., 1998; O’Leary \& Ickovics, 1995), positive changes in outlook (Joseph et al., 1993), adversarial growth (Linley \& Joseph, 2004), stress-related growth (Park et al., 1996), flourishing (Ryff \& Singer, 1998), positive by-products (McMillen, Howard, Nower, \& Chung, 2001), and positive psychological changes (Yalom $\&$ Lieberman, 1991). One of the most accepted phrases used in the literature is posttraumatic growth (PTG), which was originally coined by Tedeschi and Calhoun (1995, 
1996). PTG is defined as "positive psychological change experienced as a result of the struggle with highly challenging life circumstances" (p. 1; Tedeschi \& Calhoun, 2004).

\section{Models of Post-Traumatic Growth}

In their overview of the PTG literature, Park and Helgeson (2006) ask if PTG is best understood as a process or an outcome. Many different theoretical models have been developed to answer this question (Bhushan \& Hussain, 2007; Joseph \& Linley, 2006; Zoellner \& Maercker, 2006). Models that highlight the recuperation process from a traumatic event include the self-strengthening assessment or the creation of positive illusions (Taylor, 1983), extended model of a coping process (Davis, Nolen-Hoeksema, \& Larson, 1998; Park \& Folkman, 1997), or an outcome in its own right (Joseph \& Linley, 2005; Tedeschi \& Calhoun, 2004). Each type of model has different implications for the methods used to conduct research. Investigators who view PTG as a coping process or a positive illusion will examine how PTG affects other psychological and physical outcomes without considering growth to be an outcome itself. PTG becomes an independent variable and other health outcomes (e.g., depression, quality of life, treatment recovery) are dependent variables. In contrast to process models, outcome models identify PTG as the dependent variable and examine other aspects of health as independent variables related to PTG. Outcome models are the most widely accepted in the literature because of their comprehensive nature (Park \& Helgeson, 2006; Tedeschi \& Calhoun, 2004). For example, Tedeschi and Calhoun's (1995, 1996, 2004) functional-descriptive model (FDM) retains many of the fundamen- tal theoretical constructs present in literature while also correcting the weaknesses of other outcome models. Their model provides the most comprehensive framework for variables and processes related to PTG, as well as a detailed understanding of the components of PTG itself. FDM contains many variables, the most important are: post-traumatic personality, seismic event, rumination, selfdisclosure, social support, sociocultural influences, PTG, wisdom. In FDM, PTG is defined as a significant positive in the cognitive and emotional life of an individual that may have external manifestations in one's behavior. Development is understood as a change, in which an individual advances to a higher level of his/her current adaptation, psychological functioning and overall understanding of life (Tedeschi, Park, \& Calhoun, 1998). Development can still coexist with residual distress that has been caused by a traumatic event.

Model of life crises and personal growth by Schaefer \& Moos, (1992) outlines a process where 1) personal and environmental systems influence 2) the experience of life crises in the aftermath of trauma, which 3) affects cognitive reappraisals and coping responses, and thereby 4) results in positive outcomes. The model is dynamic since each component is able to modify other components through a feedback loop. Personal factors include sociodemographic characteristics, personality traits (e.g., resilience, optimism), temperament, motivation, physical health, and prior life experiences. Environmental factors include social systems, social support, financial resources, community characteristics, and living situations. Eventspecific factors are also considered part of the environmental system and include the severity, duration, and timing of the traumatic 
event, as well as how the event came about (i.e., random vs. human origin). Cognitive reappraisal and coping are divided into two categories in Schaefer and Moos' model (Moos \& Schaefer, 1993). Approach coping is a process of attempting to resolve crises, seek social support, reasonably analyze the situation, and identify potentially positive outcomes. In contrast, avoidance coping occurs when individuals ignore or minimize the crisis, become excessively emotional, and avoid the difficult process of recovery in favor of alternative rewards. If personal and environmental factors are favorable and approach-oriented coping is used, positive outcomes can be obtained, i.e., PTG.

\section{Paramedics, Trauma and Domains of Post-Traumatic Growth}

Besides the common sources of stress, rescue workers (paramedics) are often affected by specific burdening factors as well (Gurňáková, 2013): the responsibility for life and health of their patients, the demands for quality performance under time pressure and often times frequent lack of information, legal liability for any misconduct, not always sufficient and satisfactory material and technical equipment, physical conditions in the field work, socio-psychological conditions (interactions with patients and their relatives) and others. According to Mitchell and Everly (1996) most of the rescue workers have labeled the following as the most stressful types of incidents: death or injuries that occur in children or adolescents, death or serious injury of a co-worker, personal relationship with the victim, personal threat to self or an injury, use of firearms, events with mass injuries or casualties, identification of victims, particularly unusual death and others. These situations carry signs of traumatic incidents, among which Calhoun and Tedeschi (2006) include: the event is shocking, the occurrence arises suddenly and unexpectedly, one cannot influence the outcome, it is beyond one's ability to control and manage the situation, an individual bears the responsibility for the cause of the events, generally one is not responsible for what happened, one jeopardizes or directly causes physical or psychological injuries, the circumstances that emerge from given situations are unusual, they are exceptional and uncommon, the event causes long-term and often irreversible issues for the workers, the individual advances to the next stage in life in which one is more vulnerable. According to Paton (2005) these paramedics, who are constantly exposed to risk, may be subject to psychological imbalance when exposed to crises. The imbalance is defined as a period of time, when previously created life schemes lose their ability to organize given individual's experience, which s/he undergoes in some meaningful way. The event that causes such imbalance works also as a catalyst for change; the rescue worker must change his/her current life scheme, s/he must find a new steadiness. However, PTG is not an automatic consequence of a concurrence with a significant life situation or trauma. Such a life experience may have various effects ranging from sustaining life, living with permanent repercussions, recovering and getting back to normalcy and the highest attainable level of functioning, PTG. Tedeschi \& Calhoun (1996) acknowledge that PTG is a multidimensional construct and describe five factors of PTG: an increased sense of personal strength, changes in the ability to relate to others, greater apprecia- 
tion for life, changes in spirituality/religiosity, and the realization of new opportunities in life.

\section{The Present Research}

The aim of the study is to investigate the relationships between coping strategies enforced in situations of coping with professionally stressful situations and PTG among paramedics, and to analyze moderation effects of self-efficacy and positive/negative affectivity on the relation of observed variables.

We base our theory on the previously mentioned models: the Functional-descriptive model, Tedeschi \& Calhoun (1995, 1996, 2004) and model of life crises and personal growth, Schaefer \& Moos (1992), which highlight the significance of PTG personality determinants. Furthermore, from studies conducted on versatile samples of participants, which confirmed the relationship between ways of coping, including cognitive redefinitions, reinterpretation of events and the acceptance of that, which cannot be changed and PTG (Prati \& Pietrantoni, 2009; Calhoun et al., 2000; Cordova et al., 2001; Koenig et al., 1998; Armeli et al., 2001; Evers et al., 2001). The assumptions of moderation effects of self-efficacy and positive/negative affectivity that affect the relation of coping mechanism and PTG were based on i.e. Shen (2009), who recognized that self-efficacy is directly correlated with the use of active and positive coping mechanisms, as well as with social support. Lowe et al. (2008) discovered that people with high self-efficacy are more confident in the use of coping strategies, especially in the area of utilizing coping for specific problems. When formulating assumptions about the effects of positive and negative affectivity on the choice of coping strategies, we based our beliefs on research studies that found a relationship between these variables: extraversion and positive affectivity are connected with activation, while neuroticism and negative affectivity with inhibition (Kebza, 2005). Motowidlo, Packard, and Manning (1986) determined among health professionals, that the subjectively perceived stress and the consequent follow-up emotions (depression, anxiety) cause a deficit in interpersonal and cognitively-motivational aspects of work performance. Estrada, Isen, and Young (1997) attribute the ability to organize and integrate information (that corresponds to problemfocused coping strategies) to positive emotions. Similarly, Pilárik (2009) emphasizes the role of emotions in the decision process and states that emotions are a kind of summary assessment of the situation, in which one finds him/herself and in which one has to solve a task, and this estimate affects his/ her thought process.

\section{Methods}

\section{Participants and Procedure}

The research sample consisted of 62 paramedics aged 21-53 years old $(M=35.91$; $S D=8.97)$. There were 30 men and 32 women. Participants came from various regions of Slovakia and their experience with the work of a rescue health professional varied from 1 to 34 years $(M=7.54 ; S D=5.79)$. Participants were chosen for this research by variable selection. We approached emergency medical services with the possibility to participate in our research and participants were rescuers who agreed to take part in the research. 


\section{Materials}

Posttraumatic Growth Inventory, PTGI (Tedeschi \& Calhoun, 1996) was developed to assess positive psychosocial outcomes following traumatic experiences. The scale consisted of 21 items that provided a total growth score. ThePTGI also produced scores on five subscales: relating to others (7 items), new possibilities (5), personal strength (4), spiritual change (2), and appreciation of life (3). Participants responded to items using a 6point Likert scale ( 0 to 5 ), with a total score ranging from 0 to 105 . Higher scores indicated greater posttraumatic growth.

PTGI was created and standardized on the population of university students (coefficient $\alpha=0.90$, test-retest $r=0.71$ ). In the original version of PTGI the participant selects from a given list of various situations an event that $\mathrm{s} /$ he experienced, and which has happened more than 6 months ago. We have adjusted the beginning of the questionnaire in such a way, that we asked the participants to recall an extremely stressful event from their professional practice from memory and describe it concisely (it had to have happened more than 6 months ago). Consequently, they were asked to reflect on the individual items of the questionnaire in accordance with that situation.

Multidimensional coping inventory, COPE (Carver, Scheier, \&Weintraub, 1989, Slovak version Ficková, 1992). It is composed of 15 scales, while each contains four entries. The questionnaire contains a total of 60 items. The scales are divided into three groups: 1) the problem-focused scale (active coping, planning, suppression of competing activities, restraint coping, seeking social support - instrumental); 2) emotional focus (use of emotional social support, positive reinterpretation and growth, denial, acceptance, religious coping, turning to religion); 3) maladaptive strategies (focus on and venting of emotions, behavioral disengagement, mental disengagement). The two remaining scales - substance abuse, humor were not immediately included by the authors into any of the above mentioned groups. The questionnaire exists in two forms - dispositional and situational. Whereas the use of strategies contained in COPE may vary from occasion to occasion, we decided on the situational version - since the research objective was the infliction of situational coping effort in the duration of managing a specific stressful event.

The General Self-Efficacy Scale, GSE (Jerusalem \& Schwarzer, 1992, Slovak version Košč, Heftyová, Schwarzer, \& Jerusalem, 1993). It is a self-accounted unidimensional 10-item scale designed for an assessment of generally perceived self-efficacy in order of predicting the handling of daily obstacles and recovering from major stressful life events. The internal consistency of the scale ranges from coefficient $\alpha=0.75-0.90$. In connection with the recommendations of Bandura (1997), in order for the scale of perceived self-efficacy to be related to a certain specific life coping event, we modified the original items so that they would coincide with a specific occasion of experiencing selfefficacy (specific self-efficacy) by the participants in the initially introduced difficult situation, at the time of exposure. Participants responded to items using a 4-point Likert scale (1 to 4).

Positive and Negative Affect Scale, PANAS (Watson, Clark, \& Tellegen, 1988). It is a selfaccounted scale that contains two independent scales designed to detect positive and 
negative affectivity; these are in their shortened version created out of 20 items in the form of single-worded adjectives that express various emotional states. Participants responded to these items using a 4-point Likert scale (1 to 4). The scale may be used in order to assess the affective state in various moments in time and durations. Participants expressed their experiences with individual emotional states in relation to the initially mentioned stressful situation.

\section{Results}

\section{Descriptive Analysis}

Participants referred their answers to the questions investigating PTG on a fairly broad scale of professionally stressful situations. The most common were: injury, dying, death of a child, death of a minor (30.63\%), aggressive patient threatening a rescuer $(11.29 \%)$, mass accidents $(9.67 \%)$, personal relationship with the victim $(8.06 \%)$, extremely disfigured victims $(6.45 \%)$, suicide (of a child, pregnant woman, young person) $(4.83 \%)$, cardiopulmonary resuscitation $(4.83 \%)$. Other situations included: rescue operation in difficult conditions (in the dark, transport in a difficult terrain), conflict between a doctor and a paramedic, feelings of guilt from a failed rescue attempt, delivery of a baby in an ambulance, certain threat to a rescue worker, an injury of a rescue worker, murder with the use of a firearm, interventions of relatives in the rescue efforts, psychiatric patient in an acute psychotic episode, unsuccessful cardiopulmonary resuscitation etc. As far as the level of strain of the situation is concerned, the participants usually perceived them as a 4 (the event was labeled as 'more stressful', $35.5 \%$ ) and a 5 (the event was 'very stressful', 32.3\%). The other categories were represented less often, a response labeled with a 3 ('moderately stressful') was marked $22.6 \%$ of the time, and responses 1 and 2 ('low intensity of stress') were altogether represented with a frequency of $9.7 \%$. Thus, it may be argued that the subjective perception of a presented stressful event was very high in the majority of the participants. In confrontation with findings of other studies related to the types of particularly burdensome situations (Šeblová, Kebza, \& Vignerová, 2007; Gurňáková, 2013) we find consensus in the first place. The most frequent and most intensive survival event from the perspective of rescuers is a confrontation with death of children, young people or their cardiopulmonary resuscitation. These findings reconfirm that unnatural death (accidental, unpredictable or mass death) in comparison with natural death has serious effects on the psyche of workers who have to deal with it. At the same time, we observe in our sample an increase of intensity in the stressful event of a threat to the rescuer by an aggressive patient, in comparison with the sample of Šeblová, Kebza, and Vignerová (2007). This trend also confirms Gul'ášová's work (2014), who claims that based on the data collected in the years 2012 $-2013,80 \%$ of the patients with whom the rescuers interacted met the criteria of an aggressive patient (verbally or physically).

Time elapsed from the event. $29 \%$ of our participants presented a stressful event that took place 6 months to 1 year ago; $27.4 \%$ mentioned an occasion that happened 1 to 2 years ago; a situation that took place 2 to 5 years ago was described by $21 \%$ of participants. As many as $22.6 \%$ of rescue workers reflected on a critical event that took place over 5 years ago. 
In the sample group, total scores on the PTG scale ranged from 21 all the way up to 94 out of the possible 105, while the average value was established at $55.87(S D=18.72)$. The average value of the total PTG indicates an overall average presence of PTG. ${ }^{1}$

In the sample group, total scores on the PTG scale ranged from 21 all the way up to 94 out of the possible 105, while the average value was established at $55.87(S D=$ 18.72). The average value of the total PTG indicates an overall average presence of PTG. Due to the achieved average score compared with the maximum possible score, the most intensive growth was found in these areas of PTG: personal strength and appreciation of life.

Maximum gross score of observed coping strategies was 16 . The average score found indicates that at the time of coping with difficult situations rescuers prefer the following strategies: acceptance $(M=10.83 ; S D=$ $2.81)$; positive reinterpretation and growth $(M=9.19 ; S D=2.12)$; active coping $(M=$ 9.00; $S D=2.75)$ and planning $(M=8.56 ; S D=$ $2.67)$. The least used strategies were: substance abuse - smoking $(M=4.80 ; S D=1.56)$, humor $(M=5.35 ; S D=2.08)$ and mental disengagement $(M=5.82 ; S D=2.02)$.

\footnotetext{
${ }^{1}$ We did not find significant differences between genders in the level of overall PTG: men $(n=30)$ $M=58.83 ; S D=18.66$; women $(n=32) M=$ 53.09; $S D=18.66 ; t=1.210 ; p>.05)$. We did not find significant differences in the level of overall PTG even if we divided file based on the length of experience: rescuers with under 10 years experience $(n=48) M=55.20 ; S D=18.58$; rescuers with over 10 years experience $(n=12)$ $M=62.41 ; S D=17.88 ; t=-1.210 ; p>.05)$. We did not find a significant relation between total PTG and time elapsed since critical situation ( $r=$ $.015 ; p>0.05)$; and subjectively perceived $(r=$ $.200 ; p>0.05)$.
}

Total score of specific self-efficacy (from 14 to 40 from a total of 40 ), with an average $28.40(S D=5.64)$ speaks about sufficiently high level of perceived self-efficacy in the situation of stress. As in the emotional survival of stress situations, the rescuers describe higher level of positive $(M=25.32 ; S D$ $=4.84)$ than negative effects $(M=17.91 ; S D$ $=5.67)$. The results of descriptive statistics are in Table 1.

\section{Correlation Analysis}

In the first step, we analyzed Pearson correlations between coping strategies applied in a situation of confrontation with stressful situation and PTG in the group of paramedics. These correlations are presented in Table 2 . We found significantly positive relations between: active coping, planning, suppression of competing activities, restraint coping, seeking social support - instrumental, use of emotional social support, religious coping, focus on and venting of emotions, behavioral disengagement, substance abuse (smoking) and PTG. Significant correlations ranged from .256 to .461 , which indicated weak or semi-weak relations with the percentage of communally shared variances ranging from $6.4 \%$ to $21.2 \%$. Significantly negative relation was found between mental disengagement and PTG $\left(r=-.263 ; p<.05 ; r^{2}=\right.$ $6.9 \%$ ). Connection with the coping strategies: positive reinterpretation and growth, acceptance, humor, denial and PTG were not identified.

\section{Moderation Analysis}

In the second step we conducted a moderation analysis via hierarchical regression analysis (Blocks, Enter method). We tested 
the hypothesis that variant $Y$ (PTG) depends on the $\mathrm{Z}$ variable (coping strategies) and variable $\mathrm{Z}$ is affected by the action of $\mathrm{X}$ (model 1: self-efficacy; model 2: positive affectivity; model 3: negative affectivity). In order for the model to be considered valid, the condition that there is no relationship between $\mathrm{X}$ and $\mathrm{Y}$ must be fulfilled (this condition is met: self-efficacy $\mathrm{x}$ PTG $\mathrm{r}=-.011$; $p>.05$; positive affectivity $\times \mathrm{PTG} r=.152$; $p>.05$; negative affectivity $\times$ PTG $r=.143$; $p>.05)$.

Table 1 Descriptive statistics for posttraumatic growth, coping strategies, specific selfefficacy and affectivity

\begin{tabular}{|c|c|c|c|c|c|}
\hline $\mathrm{n}=62$ & Min. & Max. & Mdn & M & SD \\
\hline Posttraumatic growth (PTG) - Total & 21.00 & 94.00 & 56.00 & 55.87 & 18.72 \\
\hline PTG - Relating to others & 7.00 & 33.00 & 17.00 & 17.87 & 7.38 \\
\hline PTG - New possibilities & 5.00 & 23.00 & 12.00 & 12.27 & 5.07 \\
\hline PTG - Personal strength & 4.00 & 24.00 & 12.00 & 11.88 & 4.25 \\
\hline PTG - Spiritual change & 2.00 & 10.00 & 3.00 & 4.27 & 2.43 \\
\hline PTG - Appreciation of life & 3.00 & 17.00 & 10.00 & 9.56 & 4.37 \\
\hline Active coping & 4.00 & 16.00 & 8.00 & 9.00 & 2.75 \\
\hline Planning & 4.00 & 15.00 & 8.00 & 8.56 & 2.67 \\
\hline Suppression of competing activities & 4.00 & 13.00 & 7.00 & 7.19 & 2.23 \\
\hline Restraint coping & 4.00 & 14.00 & 8.00 & 7.72 & 2.36 \\
\hline Seeking social support & 4.00 & 13.00 & 7.00 & 7.33 & 2.08 \\
\hline Use of emotional social support & 4.00 & 16.00 & 8.00 & 7.88 & 2.31 \\
\hline Positive reinterpretation and growth & 5.00 & 17.00 & 9.00 & 9.19 & 2.12 \\
\hline Acceptance & 4.00 & 16.00 & 11.00 & 10.83 & 2.81 \\
\hline Religious coping & 4.00 & 15.00 & 6.00 & 6.80 & 2.74 \\
\hline Focus on and venting of emotions & 4.00 & 15.00 & 7.50 & 7.53 & 1.90 \\
\hline Denial & 4.00 & 12.00 & 7.00 & 6.85 & 1.83 \\
\hline Behavioral disengagement & 4.00 & 14.00 & 7.00 & 7.03 & 2.17 \\
\hline Mental disengagement & 4.00 & 13.00 & 5.00 & 5.82 & 2.02 \\
\hline Substance abuse & 4.00 & 11.00 & 4.00 & 4.80 & 1.56 \\
\hline Humor & 4.00 & 12.00 & 4.00 & 5.35 & 2.08 \\
\hline Specific self-efficacy & 14.00 & 40.00 & 30.00 & 28.40 & 5.64 \\
\hline Positive affectivity & 16.00 & 34.00 & 25.00 & 25.32 & 4.84 \\
\hline Negative affectivity & 10.00 & 34.00 & 16.00 & 17.91 & 5.67 \\
\hline
\end{tabular}

Note. Min. - minimum, Max. - maximum, Mdn - median, $\mathrm{M}$ - mean, $\mathrm{SD}$ - standard deviation 
Table 2 Correlation between coping strategies, specific self-efficacy, affectivity and posttraumatic growth in paramedics (Pearson correlations)

\begin{tabular}{|c|c|c|c|c|c|c|}
\hline $\mathrm{n}=62$ & $\begin{array}{c}\text { Posttraum. } \\
\text { growth - } \\
\text { Total }\end{array}$ & $\begin{array}{l}\text { Posttraum. } \\
\text { growth - } \\
\text { Relating to } \\
\text { others }\end{array}$ & $\begin{array}{l}\text { Posttraum. } \\
\text { growth - } \\
\text { New } \\
\text { possibilities }\end{array}$ & $\begin{array}{c}\text { Posttraum. } \\
\text { growth - } \\
\text { Personal } \\
\text { strength }\end{array}$ & $\begin{array}{c}\text { Posttraum. } \\
\text { growth - } \\
\text { Spiritual } \\
\text { change }\end{array}$ & $\begin{array}{l}\text { Posttraum. } \\
\text { growth - } \\
\text { Appreciation } \\
\text { of life }\end{array}$ \\
\hline Active coping & $.400^{* *}$ & $.343^{* *}$ & $.461^{* *}$ & .246 & .149 & $.273^{*}$ \\
\hline Planning & $.355^{* *}$ & $.312^{*}$ & $.422 * *$ & .058 & $.314^{*}$ & $.273^{*}$ \\
\hline $\begin{array}{l}\text { Suppression of competing } \\
\text { activities }\end{array}$ & $.307^{*}$ & $.257^{*}$ & $.343 * *$ & .106 & $.353 * *$ & .183 \\
\hline Restraint coping & .194 & .165 & $.272 *$ & .119 & .147 & .040 \\
\hline Seeking social support & $.290^{*}$ & $.295^{*}$ & $.256^{*}$ & $.257^{*}$ & .140 & .121 \\
\hline Use of emotional social support & $.303^{*}$ & $.316^{*}$ & .186 & .247 & .175 & .212 \\
\hline $\begin{array}{l}\text { Positive reinterpretation and } \\
\text { growth }\end{array}$ & .213 & .190 & .176 & .224 & .145 & .087 \\
\hline Acceptance & .015 & -.064 & .049 & .189 & -.053 & -.040 \\
\hline Religious coping & .179 & .219 & .030 & -.010 & $.524 * *$ & .083 \\
\hline $\begin{array}{l}\text { Focus on and venting of } \\
\text { emotions }\end{array}$ & & & & & & \\
\hline Denial & $.371^{* *}$ & $.393^{* *}$ & .213 & $\begin{array}{l}.360^{* *} \\
-160\end{array}$ & .141 & .249 \\
\hline $\begin{array}{l}\text { Behavioral disengagement } \\
\text { Mental disengagement }\end{array}$ & $\begin{array}{l}.043 \\
.256^{*}\end{array}$ & $\begin{array}{l}.116 \\
.334 * *\end{array}$ & $\begin{array}{l}.029 \\
.145\end{array}$ & .016 & $.253^{*}$ & $\begin{array}{l}.04 / \\
.207\end{array}$ \\
\hline Substance abuse & -.082 & -.023 & -.121 & $-.263^{*}$ & .200 & -.027 \\
\hline \multirow{2}{*}{ Humor } & .038 & .101 & -.047 & -.099 & $.354 * *$ & -.056 \\
\hline & -.043 & .030 & -.116 & -.005 & .090 & -.144 \\
\hline Specific self-efficacy & -.011 & -.013 & -.080 & .109 & -.026 & -.025 \\
\hline Positive affectivity & .152 & .120 & .170 & .203 & -.072 & .093 \\
\hline Negative affectivity & .143 & .216 & .176 & -.006 & -.029 & .066 \\
\hline
\end{tabular}

Note. ${ }^{*} \mathrm{p}<.05 ;{ }^{* *} \mathrm{p}<.01$

The results of the two-step regression analysis are displayed in Tables 3 and 4 . These Tables include regression coefficients of analysis in the first block (coping strategy and moderator) and regression coefficients of analysis in the second block (added interaction predictor calculated as a product of the two variables used in the first block).
The dependent variable in all of the cases was PTG. Having taken into consideration the frequency of the analyses (45 altogether) we chose to present only 2 of them in our study, in which we detected a significant moderation effect.

Table 3 presents results of the moderation analysis of the self-efficacy variable on the 
Table 3 Hierarchical regression analysis testing moderating effect of specific self-efficacy on the relationship between coping strategy: substance use and posttraumatic growth in paramedics

\begin{tabular}{lcccc}
\hline $\mathrm{n}=62$ & $B$ & $\Delta R^{2}$ & $F$ & $p$ \\
\hline Step 1 & .039 & & & \\
substance abuse & .002 & .001 & .042 & .959 \\
specific self-efficacy & & & & \\
Step 2 & & & & \\
substance abuse & .183 & .093 & 5.923 & $.018^{*}$ \\
specific self-efficacy & -.034 & & & \\
substance abuse x specific self-efficacy & $.344^{*}$ & & & \\
Total & & .094 & & \\
\hline
\end{tabular}

Note. Dependent variable: Posttraumatic growth

$* p<.05$

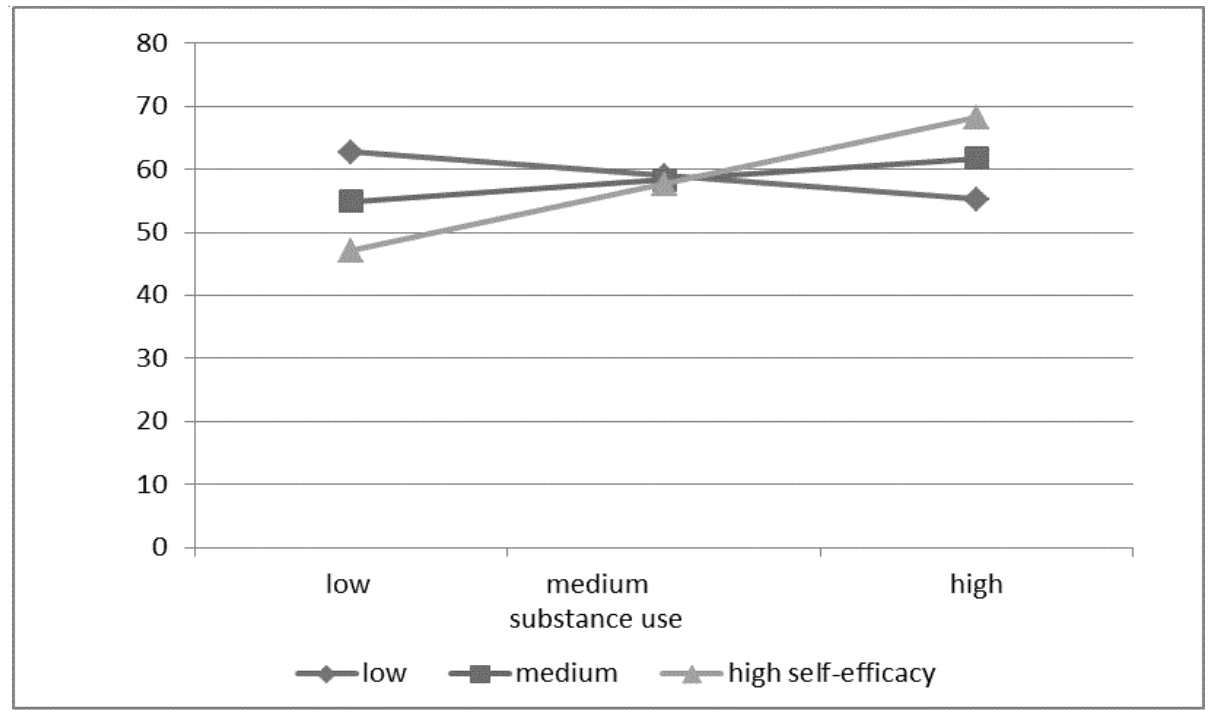

Figure 1 Relationship between coping strategy: substance use and posttraumatic growth at low, medium and high specific self-efficacy in paramedics 
Table 4 Hierarchical regression analysis testing moderating effect of positive affectivity on the relationship between coping strategy: suppression of competing activities and postraumatic growth in paramedics

\begin{tabular}{lllll}
\hline $\mathrm{n}=62$ & $B$ & $\Delta R^{2}$ & $F$ & $p$ \\
\hline $\begin{array}{l}\text { Step } 1 \\
\text { suppression of competing activities }\end{array}$ & $.292^{*}$ & & & \\
positive affectivity & .115 & .107 & $3.545^{*}$ & $.035^{*}$ \\
Step 2 & & & \\
suppression of competing activities & $.265^{*}$ & & & \\
positive affectivity & .137 & $.076^{*}$ & 5.365 & $.024^{*}$ \\
suppression of competing activities & $.277^{*}$ & & & \\
x positive affectivity & & & & \\
Total & & $.183^{* *}$ & & \\
\hline
\end{tabular}

Note. Dependent variable: Posttraumatic growth

$* \mathrm{p}<.05 ; * * \mathrm{p}<.01$

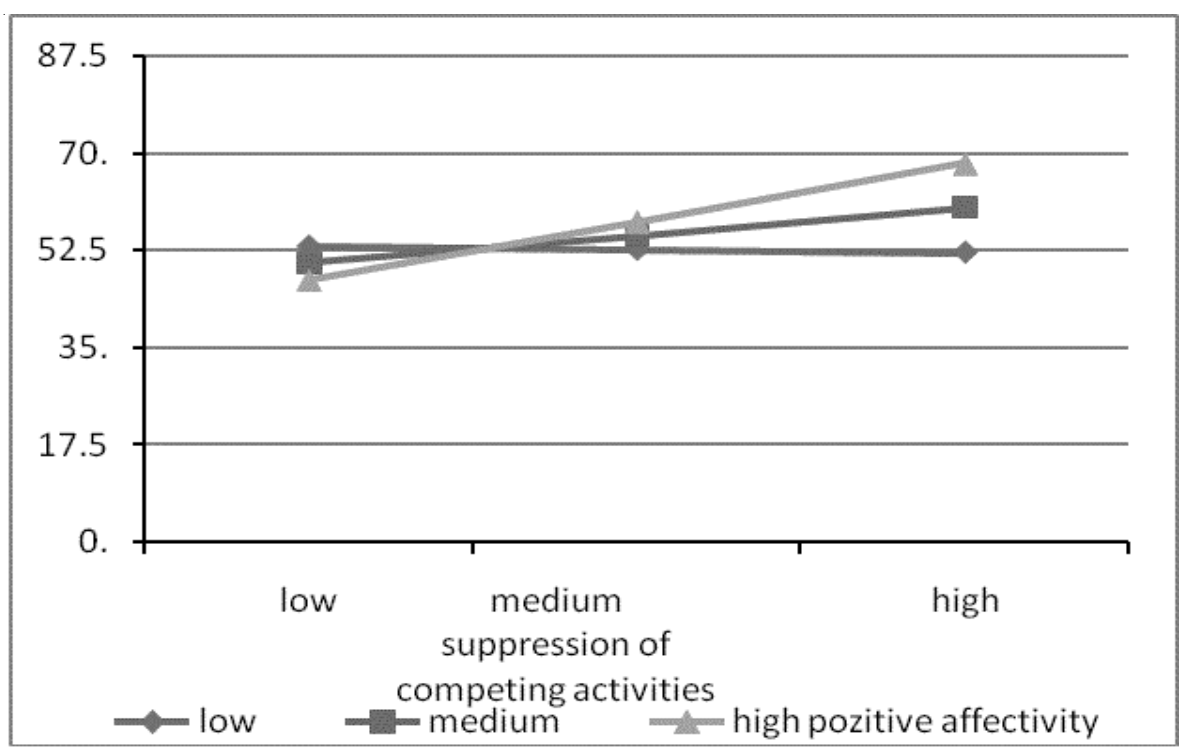

Figure 2 Relationship between coping strategy: suppression of competing activities and posttraumatic growth at low, medium and high positive affectivity in paramedics 
relation between coping strategies with substance abuse and PTG. The interactive variable, which was added in the second step of the regression analysis, is a significant predictor of PTG and it helps to explain the $9.3 \%$ variance of PTG (small effect size) (Cohen, 1992).

Figure 1 shows direction of the interaction effect. Coping strategy: substance use positively predicted posttraumatic growth in paramedics only at high levels of specific selfefficacy $(B=6.75 ; p<.05)$, but not at medium $(B=2.18 ; p>.05)$ and low levels of specific self-efficacy $(B=-2.37 ; p>.05)$.

Table 4 presents the results of the moderation analysis of the positive affectivity variable and the relationship between the suppression of competing activities and PTG. The interactive variable, which was added in the second step of the regression analysis, is a significant predictor of PTG and it helps to explain the $7.6 \%$ variance of PTG (small effect size) (Cohen, 1992).

Figure 2 shows the direction of the interaction effect. Coping strategy: suppression of competing activities positively predicted posttraumatic growth in paramedics at high levels $(B=4.68 ; p<.01)$ and at medium levels of positive affect $(B=2.22 ; p<.05)$, but not at low levels of positive affect $(B=-.23 ; p>$ $.05)$.

Moderation effect of negative affectivity between the relationship of the observed coping strategies and PTG was not detected.

\section{Discussion}

\section{Coping Strategies and Posttraumatic Growth}

It was observed among the rescuers that in a professional traumatic situation the cop- ing strategies such as active coping, planning, suppression of competing activities, restraint coping, seeking social support instrumental, use of emotional social support, religious coping, focus on and venting of emotions, behavioral disengagement, mental non- disengagement ("mental activation") - are the origins of PTG. These strategies help paramedics not only eliminate stress stemming from a traumatic experience, but they also direct them towards restoration of control, security and safety via searching for social and emotional support, turning towards God and faith. From the findings it can be concluded that rescuers, who utilize the 'potential of team work' as a searching tool for figuring out how to proceed, as well as a tool for searching for moral and emotional support, affection and understanding within the team in a situation that requires handling a critical situation, have a higher potential for PTG. This finding also supports the justification for the current process of initializing the offering of peer support for coping with situations, stabilization, processing and integrating traumatic professional events in the lives of the affected paramedics. Schroevers et al. (2010) report that the support from other people may help people find a positive meaning and perceive PTG.

In research, strategies focused on emotions are often connected with distress and dysfunction; however this is due to the traditional conceptualization of emotions as disorganized and maladaptive qualities. On the contrary, new studies highlight the adaptive nature of emotions and their expression while adapting to stressful life events (Stanton, Kirk, Cameron, \& Danoff-Burg, 2000; Zautra, 1996 in: Folkman \& Moskowitz 2004; Garnefski \& Kraaij, 2006). Lazarus and 
Folkman (1984) also report that strategies aimed at emotions may help maintain mental balance. In this context, we perceive the coping strategy 'focus and venting of emotions' among rescuers as adaptive. Ventilating and expressing emotions in the cases of a limitexceeding load can be a highly functional coping behavior aimed at managing pressure during a critical event. Adaptation of emotional coping is demonstrated mainly in situations that are irreversible and in which a successful solution is not possible - i.e., situations associated with loss, death, etc. (Ruiselová, 2006). This finding is suggestive, especially when one realizes that the display of emotions among the rescue forces is often regarded as a sign of weakness and incompetence. Appreciation for these coping strategies may represent a potential source for development. This supports the finding of significant positive relationships between the strategy 'focus on and venting of emotions' and PTG, as well as PTG in the area of relationships with others and personal development (personal development in terms of i.e., feelings of elevated self-confidence, as well as life events management).

It has also been found that in the group of paramedics there is a positive correlation between behavioral disengagement and PTG. This is a coping strategy, which Carver, Schemer, and Weintraub (1989) classified as maladaptive. The theoretical model of behavioral self-regulation by Carver and Scheier (1985 in: Ficková, 1992) predicts that the expectation of successful outcomes causes a reestablishment for need to achieve a goal. However, if the expectations are negative, there is a decrease in activity or even a complete 'shut-off' in order to achieve a goal. In some situations, with which rescuers are confronted during their practice, positive outcomes cannot be expected given their nature (interventions in successful suicides, accidents resulting in injuries that are incompatible with life, etc.). Based on communication with the operator of the paramedic call center, rescuers are not capable of predicting the level and extent of the patient's injuries. Upon arrival on site, rescue teams often have no other choice but to give up the attempt to achieve their goal (successful rescue, stabilization, and transport to a medical facility). From the paramedic's perspective, such interventions are rated as extremely stressful and are associated with feelings of hopelessness. The frequency of these cases was very high in our research. Despite the intensity of these events and situational feelings of helplessness, results indicate a significant positive relation between behavioral shut-off and PTG, as well as PTG in the area of relations with other people and changes in the spiritual area. Efforts to integrate these events into the lives of paramedics may manifest themselves as heightened interests in contemplating questions of existence and overall meaning of life, in which the inclination towards spirituality may be helpful.

\section{Specific Self-Efficacy as Moderator of the Relations between Coping Strategies and Post-Traumatic Growth}

Moderator analysis pointed out towards the moderation effect of self-efficacy only in one case of the relationship between the coping strategy 'substance abuse' (smoking) and PTG. Substance abuse positively predicts PTG only in paramedics with high level of self-efficacy. Despite the fact that smoking (directly in situation of coping with stress) represents "a simple behavioral coping strategy" it has a personal meaning for 
rescuers. They use it when they need "to take a break" and it is also an opportunity for informal talk about what has happened. In such cases 'substance abuse' can be an accompanying phenomenon for seeking social support $\left(r=.396 ; p<.001 ; r^{2}=15.7 \%\right)$ or focus on and venting of emotions $(r=.354$; $p<.001 ; r^{2}=12.5 \%$ ), which confirms the significantly positive intercorrelations of these strategies. "Being sensitive to one's own needs and finding ways of taking care of oneself" in over limit stress situations is in line with the definition of people with high self-efficacy. Bandura $(1994,1997)$ defines self-efficacy as 1) one's belief in their ability to succeed in a given situation or general personal belief in their own ability to cope with life difficulties and challenges, 2) one's belief in their ability to control their own functioning and events that affect their lives. Due to the post-traumatic development found among paramedics with high level of selfefficacy, who used substances in order to overcome a stressful situation, it may be observed that the search for an alternative source providing stabilization may externalize as a change and a development in mental or spiritual area. Similarly, Wadsworth et al. (2004) claim that there is often a shift (in connection with PTG of an individual) from simple behavioral coping strategies to strategies focused on internal survival.

Positive Affectivity as Moderator of the Relations between Coping Strategies and Posttraumatic Growth

Moderator analysis pointed towards the moderation effect of positive affectivity only in one case of the relationships - coping strategy 'suppression of competing activities' and PTG. Suppression of competing activities positively predicts $\mathrm{PTG}$ in paramedics with a high or medium level of positive affectivity.

From these findings it may be concluded that among paramedics, who are able to hold on to their positive affectivity during a critical incident (experiencing emotion such as interest, excitement, pride, inspiration, perception of ability, determination, attention, vigorousness and strenuousness), that PTG occurs in relation with the choice of coping behavior in terms of suppression of competing activities - suppressing rescuer's attention to other activities in which he might engage, in order to concentrate more completely on dealing with the stressor. It is suspected that positive emotional tuning enables the paramedic to procrastinate, which is secondary in a given situation. Similarly, Andrews, Ainley, and Frydenberg (2004) found significant positive correlations of productive coping style with positive emotions and with self-efficacy. It has been shown that positive emotions play an important role in resolving a problem, whilst more than a half of such emotions are: hopeful and happy. Estrada, Isen, and Young (1997) found, while examining the impact of positive emotions in the diagnostic process of doctors of internal medicine, that internists who analyze patients' protocols with positive emotions came up with a diagnosis much faster and without errors. Authors attribute this fact to the positive emotions' ability to organize and integrate information. Doctors, who were under the influence of positive emotions, were also more open to new ideas and they pursued less cognitive operations leading to verification, validation and control of hypotheses. In general, it is thus assumed that positive emotions help one achieve an adequate decision by extending the scope of attention 
and they increase the capacity and repertoire of possible actions (i.e., Fredrickson \& Braningan, 2005).

\section{Limitations and Future Research}

The study's ambition was pilot examining of personal factors and their relation to the occurrence of PTG in a specified sample of medical rescuers. The limit of this research is the sample size, which might have affected the results, particularly the moderating analysis. Problematic can also be the PANAS scale, which we used to study how rescuers felt in the time of concrete high stressful intervention. In the future, it can be meaningful to control for the effect of time that has passed since the situation - it is possible that after a long time memories can have a different quality. From our perspective this study opens new perspectives to a further examination of PTG in medical rescuers. It could also be important to conduct detail analysis of the relation between coping and PTG or other variables (self-efficacy, affectiveness, regulation of emotions) according to the situation types, e.g., the situation in which rescuers felt helplessness (did not have a positive solution) vs. situations where they could act more meaningfully and contribute to a better outcome.

Received October 22, 2015

\section{References}

Abraído-Lanza, A. F., Guier, C., \& Colón, R. M. (1998). Psychological thriving among Latinas with chronic illness. Journal of Social Issues, 54, 405-424.

Affleck, G., \& Tennen, H. (1996). Constructing benefits from adversity: Adaptational significance and dispositional underpinnings. Journal of Personality, 64, 899-922.
Andrews, M., Ainley, M., \& Frydenberg, E. (2004). Adolescent engagement with problem solving tasks: The role of coping style, self-efficacy, and emotions. Paper presented at the 2004 AARE International Conference. Available from http:// www.aare.edu.au/04pap/and04761.pdf

Antoni, M. H., Lehman, J. M., Kilbourn, K. M., Boyers, A. E., Culver, J. L., Alferi, S. M., et al. (2001). Cognitive-behavioral stress management intervention decreases the prevalence of depression and enhances benefit finding among women under treatment for early-stage breast cancer. Health Psychology, 20, 20-32.

Armeli, S., Gunthert, K. C., \& Cohen, L. H. (2001). Stressor appraisals, coping, and post event outcomes: The dimensionality and antecedents of stress-related growth. Journal of Social and Clinical Psychology, 20, 366-395.

Bandura, A. (1994). Self-efficacy. In R. J. Corsini (Ed.), Encyclopedia of Psychology. 2nd Ed., 3, 368-369. New York: Wiley.

Bandura, A. (1997). Self-efficacy: The exercise of control. New York: Freeman.

Bhushan, B., \& Hussain, D. (2007). Posttraumatic growth: Theory, research, and issues. Psychological Studies, 52, 45-53.

Calhoun, L. G., Cann, A., Tedeschi, R. G., \& McMillan, J. (2000). A correlational test of the relationship between posttraumatic growth, religion, and cognitive processing. Journal of Traumatic Stress, 13, 521-527.

Calhoun, L. G., \& Tedeschi, R. G. (2006). Handbook of posttraumatic growth: Research and practice (p. 387). Mahwah, New Jersey: Lawrence Erlbaum Associates.

Carver, C. S., Scheier, M. F., \& Weintraub, J. K. (1989). Assessing coping strategies: A theoretically based approach. Journal of Personality and Social Psychology, 56, 267-283.

Cohen, J. (1992). A Power Primer. Psychological Bulletin, 11(1), 155-159. Retrieved from http:// www.apa.org/pubs/journals/bul/

Cordova, M. J., Cunningham, L. L., Carlson, C. R., \& Andrykowski, M. A. (2001). Posttraumatic growth following breast cancer: A controlled comparison study. Health Psychology, 20, 176-185.

Davis, C. G., Nolen-Hoeksema, S., \& Larson, J. (1998). Making sense of loss and benefiting from the experience: Two construals of meaning. Journal of Personality and Social Psychology, 75, 561-574.

Estrada, C. A., Isen, A. M, \& Young, M. (1997). PA facilitates integration of information and de- 
creases anchoring in reasoning among physicians. Organizational and Human Decision Processes, $72,117-135$.

Evers, A. W., Kraaimaat, F. W., van Lankveld, W., Jongen, P. J., Jacobs, J. W., \& Bijlsma, J. W. (2001). Beyond unfavorable thinking: The illness cognition questionnaire for chronic diseases. Journal of Consulting and Clinical Psychology, 69, 1026-1036.

Ficková, E. (1992). Zvládanie stresu: Teórie, mechanizmy, stratégie. In Z. Ruiselová, I. Ruisel (Eds.), Praktická inteligencia I. (pp. 50-65). Bratislava, ÚEP SAV.

Folkman, S., \& Moskowitz, J. T. (2004). Coping: Pitfalls and promise. Annual Review of Psychology, 55, 647-654. doi: 10.1146/annurev.psych. 55.090902 .141456 .

Fredrickson, B. L., \& Branigan, C. (2005). Positive emotions broaden the scope of attention and thought-action repertoires. Cognition \& Emotion, 19, 313-332.

Garnefski, N., \& Kraaij, V. (2006). Cognitive emotion regulation questionnaire - development of a short 18-item version (CERQ-short). Personality and Individual Differences, 41, 1045 1053.

Gul'ášová, M. (2014). Prvá pomoc pri strese zdravotníckeho záchranára. Od pochopenia cez prevenciu až ku krízovej intervencii. Vyd. ÓAPFO.

Gurňáková, J. (2013). Zdroje akútneho a chronického stresu v práci zdravotníckych profesionálov. In J. Gurňáková et al., Rozhodovanie profesionálov: Sebaregulácia, stress a osobnost (pp. 34-62). Bratislava, Ústav experimentálnej psychológie SAV.

Jerusalem, M., \& Schwarzer, R. (1992). Self-efficacy as a resource factor in stress appraisal processes. In R. Schwarzer (Ed.), Self-efficacy Thought control of action (pp. 195-213). Washington, DC: Hemisphere.

Joseph, S., \& Linley, P. A. (2005). Positive adjustment to threatening events: An organismic valuing theory of growth through adversity. Review of General Psychology, 9, 262-280.

Joseph, S., \& Linley, P. A. (2006). Growth following adversity: Theoretical perspectives and implications for clinical practice. Clinical Psychology Review, 26, 1041-1053.

Joseph, S., Williams, R., \& Yule, W. (1993). Changes in outlook following disaster: The preliminary development of a measure to assess positive and negative responses. Journal of Traumatic Stress, $6,271-279$.
Kebza, V. (2005). Psychosociálni determinant zdraví. Praha: Academia.

Koenig, H. G., Pargament, K. I., \& Nielsen, J. (1998). Religious coping and health status in medically ill hospitalized older adults. Journal of Nervous and Mental Disorders, 186, 513-521.

Košč, M., Heftyová, E., Schwarzer, R., Jerusalem, M. (1993). Slovakian Adaptation of the General Self-Efficacy Scale [online]. [cited 2013-10-22]. Available from: http://userpage.fu-berlin.de/ $\sim$ health/slovak.htm

Lazarus, R. S., \& Folkman, S. (1984). Stress, appraisal and coping. New York: Springer.

Linley, P. A., \& Joseph, S. (2004). Positive change following trauma and adversity: A review. Journal of Traumatic Stress, 17, 11-21.

Lowe, R., Cockshott, Z., Greenwood, R., Kirwan, J. R., Almeida, C., Richards, P., et al. (2008). Selfefficacy as an appraisal that moderates the coping-emotion relationship: Associations among people with rheumatoid arthritis. Psychology and Health, 23, 155-174.

McMillen, C., Howard, M. O., Nower, L., \& Chung, S. (2001). Positive by-products of the struggle with chemical dependency. Journal of Substance Abuse Treatment, 20, 69-79.

McMillen, C., Zuravin, S., \& Rideout, G. (1995). Perceived benefit from child sexual abuse. Journal of Consulting and Clinical Psychology, 63, 1037-1043.

Mitchell, J. T., \& Everly, G. S. (1996). Critical Incident Stress Debriefing (CISD): An operations manual for the prevention of traumatic stress among emergency services and disaster workers. Second Edition. Ellicott City, MD: Chevron Publishing.

Moos, R. H., \& Schaefer, J. A. (1993). Coping resources and processes: Current concepts and measures. In L. Goldberger \& S. Breznitz (Eds.), Handbook of stress: Theoretical and clinical aspects (2nd ed.), (pp. 234-257). New York: Free Press. Motowidlo, S. J., Packard, J. S., \& Manning, M. R. (1986). Occupational stress: Its causes and consequences for job performance. Journal of Applied Psychology, 71(4), 618-629.

O’Leary, V. E., \& Ickovics, J. R. (1995). Resilience and thriving in response to challenge: An opportunity for a paradigm shift in women's health. Women's Health: Research on Gender, Behavior, and Policy, 1, 121-142.

Park, C. L., Cohen, L. H., \& Murch, R. L. (1996). Assessment and prediction of stress-related growth. Journal of Personality, 64, 71-105. 
Park, C. L., \& Helgeson, V. S. (2006). Introduction to the special section: Growth following highly stressful life events-current status and future directions. Journal of Consulting and Clinical Psychology, 74, 791-796.

Park, C. L., \& Folkman, S. (1997). Meaning in the context of stress and coping. Review of General Psychology, 1, 115-144.

Paton, D. (2005). Preparing for a responding to adverse events: Perspectives on natural and political hazards, The Australasian Journal of Disaster and Trauma Studies, 1, 1-3.

Pilárik, L. (2009). Emócie a rozhodovanie: Emočná inteligencia a duálnoprocesové teórie rozhodovania. In L'. Pilárik \& E. Jurišová (Eds.), Rozhodovanie $v$ kontexte kognície, osobnosti a emócii (pp. 57-64). Nitra: FSVaZ UKF

Prati, G., \& Pietrantoni, L. (2009). Optimism, social support, and coping strategies as factors contributing to posttraumatic growth: A metaanalysis. Journal of Loss and Trauma, 14, 364388.

Ruiselová, Z. (2006). Štýly zvládania zát'aže. In Z. Ruiselová a kol., Štýly zvládania zát'aže a osobnost' (pp. 9-20). Ústav experimentálnej psychológie SAV, Bratislava.

Ryff, C. D., \& Singer, B. (1998). The contours of positive human health. Psychological Inquiry, 9, 1-28.

Shen, Y., E. (2009). Relationships between selfefficacy, social support and stress coping strategies in Chinese primary and secondary school teachers. Stress and Health, 25(2), 129-138.

Schaefer, J. A., \& Moos, R. H. (1992). Life crises and personal growth. In B. N. Carpenter (Ed.), Personal coping: Theory, research, and application (pp. 149-170). Westport, CT: Praeger.

Schroevers, M. J., Helgeson, V. S., Sanderman, R., \& Ranchor, A. V. (2010). Type of social support matters for prediction of posttraumatic growth among cancer survivors. Psycho-Oncology, 19, 46-53.

Stanton, A. L., Kirk, S. B., Cameron, C. L., \& DanoffBurg, S. (2000). Coping through emotional approach: Scale construction and validation. Journal of Personality and Social Psychology, 78, 1150-1169.
Šeblová, J., Kebza, V., \& Vignerová, J. (2007). Zátěž a stres pracovníků záchranných služeb v České republice. Československá Psychologie, LI, 4, 404417.

Taylor, S. E. (1983). Adjustment to threatening events: A theory of cognitive adaptation. American Psychologist, 38, 1161-1173.

Tedeschi, R. G., \& Calhoun, L. G. (1995). Trauma and transformation: Growing in the aftermath of suffering. Thousand Oaks, CA: Sage.

Tedeschi, R. G., \& Calhoun, L. G. (1996). The posttraumatic growth inventory: Measuring the positive legacy of trauma. Journal of Traumatic Stress, 9, 455-471.

Tedeschi, R. G., \& Calhoun, L. G. (2004). Posttraumatic growth: Conceptual foundations and empirical evidence. Psychological Inquiry, 15, 118.

Tedeschi, R. G., Park, C. L., \& Calhoun, L. G. (1998). Posttraumatic growth: Conceptual issues. In R. Tedeschi \& L. Calhoun (Eds.) Posttraumatic growth: Positive changes in the aftermath of crisis (pp. 1-22). Mahwah, NJ: Lawrence Earlbaum Associates.

Tennen, H., Affleck, G., Urrows, S., Higgins, P., \& Mendola, R. (1992). Perceiving control, construing benefits, and daily processes in rheumatoid arthritis. Canadian Journal of Behavioural Science, 24, 186-203.

Wadsworth, M. E., Gudmundsen, G. R., Raviv, T., Ahlkvist, J. A., McIntosh, D. N., Kline, G., et al. (2004). Coping with terrorism: Age and gender differences in effortful and involuntary responses to September 11 th. Applied Developmental Science, 8, 143-157.

Watson, D., Clark, L. A., \& Tellegen, A. (1988). Development and validation of brief measures of positive and negative affect: The PANAS scales. Journal of Personality and Social Psychology, 54(6), 1063-1070.

Yalom, I. D., \& Lieberman, M. A. (1991). Bereavement and heightened existential awareness. Psychiatry: Journal for the Study of Interpersonal Processes, 54, 334-345.

Zoellner, T., \& Maercker, A. (2006). Posttraumatic growth in clinical psychology: A critical review and introduction of a two component model. Clinical Psychology Review, 26, 626-653. 